\title{
Determinant of Fishing Performance in Comoros
}

\author{
Mamudu Daffay ${ }^{1}$, Elfakiri Ali Mohamed ${ }^{2}$ \\ ${ }^{1}$ Faculty of Arts and Social Sciences, Department of Economics, Zanzibar University, Zanzibar, Tanzania \\ ${ }^{2}$ Department of Economic, Zanzibar University, Zanzibar, Tanzania \\ Email: *papaishmaeldaff@yahoo.com, elfakiriali8@gmail.com
}

How to cite this paper: Daffay, M., \& Ali Mohamed, E. (2021). Determinant of Fishing Performance in Comoros. Journal of Human Resource and Sustainability Studies, 9, 630-639.

https://doi.org/10.4236/jhrss.2021.94040

Received: October 27, 2021

Accepted: December 27, 2021

Published: December 30, 2021

Copyright $\odot 2021$ by author(s) and Scientific Research Publishing Inc. This work is licensed under the Creative Commons Attribution International License (CC BY 4.0).

http://creativecommons.org/licenses/by/4.0/

\begin{abstract}
This study explores the determinant fishing performance in Comoro. We estimate a model with a DOLS specification backed by Engle-Granger test for cointegration in order to confirm a long-run relationship. This paper identifies the pricing policy as the key determinant of fishing performance and, encourages efficient government support based on clear understanding of the needs of fishers in Comoros to reduce problem and enhance current catch levels that maintain a higher yearly potential yield. Finally, we stress the importance of controlling illegal fishers as well as the regulating of the number of fishing vessels in Comoros.
\end{abstract}

\section{Keywords}

Dynamic Ordinary Least Square, Skipjack Tuna, Endogeneity, Normality Test

\section{Introduction}

Fishing is a prehistoric practice dating back at least 40,000 years. Since the 16th century, fishing vessels have been able to cross oceans in pursuit of fish, and since the 19th century it has been possible to use larger vessels and in some cases process the fish on board.

Comoros, also known as the Comoro Islands is among the world's poorest and least developed nations, it is an archipelago of volcanic islands off the south-east coast of Africa. Union of Comoros is consisted for four islands inside of Indian Ocean. Comoros archipelagos are about $350 \mathrm{~km}$ from North-West of Madagascar and $250 \mathrm{~km}$ south-east of Mozambique.

This country has inadequate transportation links, with a young and rapidly increasing population, and few natural resources coupled with low educational level of the labor force has contributed to a subsistence level of economic activi- 
ty, with high unemployment, and a heavy dependence on foreign grants and technical assistance. As a result, most of the inhabitants make their living from subsistence agriculture and fishing. The government is working to upgrade education and technical training, to privatize commercial and industrial enterprises, to improve health services, to diversify exports, to promote tourism, and to reduce the high population growth rate.

Since the latter part of the 1980s, the Comoros has made headway in developing fisheries as a source of export earnings. Comoros' ambitions for its fisheries, which are largely artisanal, include the entrenchment of the co-management concept that entails involving fishing communities in decision-making on the management of their fisheries so as to minimize overfishing and boost the economic benefits of the fishing industry to those communities.

The government's strategy in ensuring Comoros fishers reap economic benefits includes investing in value addition, which includes modern infrastructure to support artisanal fisheries. This infrastructure includes new landing sites, cold storage, and ice machines, all which require a reliable supply of electricity. However, the most technology used for fishing includes Gill net, Set net, Hand line, Locker or rack net and sometime long line.

In Comoros fishing is the second most important sector of the economy after agriculture (Bakar, 2013). Natural resources and biodiversity constitute a major potential for the national economy. Its fishery potential, which is mainly composed of tuna and tuna like species, is an estimated 33,000 MT per year (Hidemichi Fujii, et al., 2014). The 8000 fishermen represent 10 percent of the population.

Most fishermen still use traditional wooden canoes, but over the last 20 years, small motorized fiberglass boats have been introduced into artisanal fishing, and account for about one third of boats. The availability of motorized boats along with fish aggregating devices has enabled artisanal fishers to travel further offshore and obtain some varieties of tuna, substantially increasing catches. Since 2006 to 2019 fishing catches have continuously increase, however, the growth rate has been very minimal, lingering around the $2 \%$ margin (see Figure 1, Figure 2).

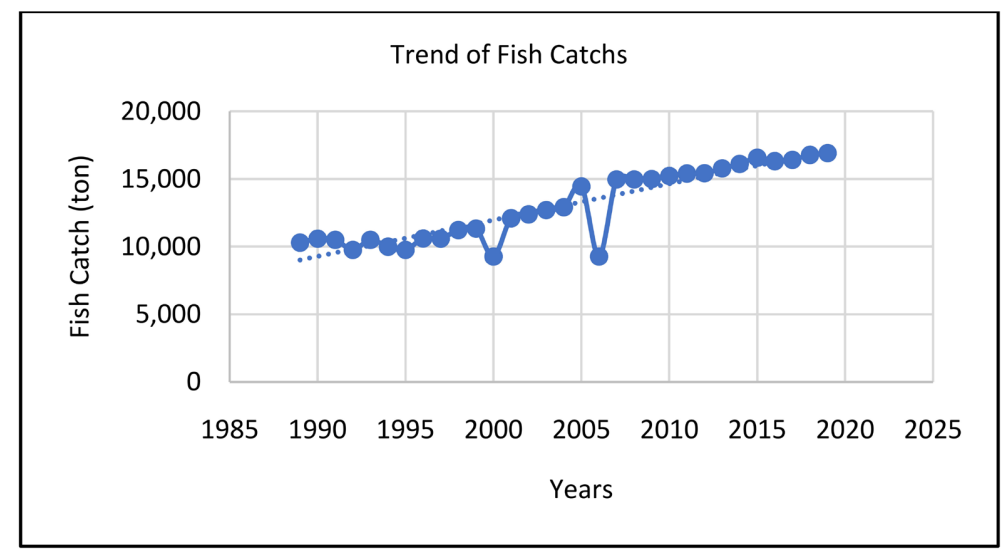

Figure 1. Trend of fish catch in Comoros. Source: General office of fisheries resources. 


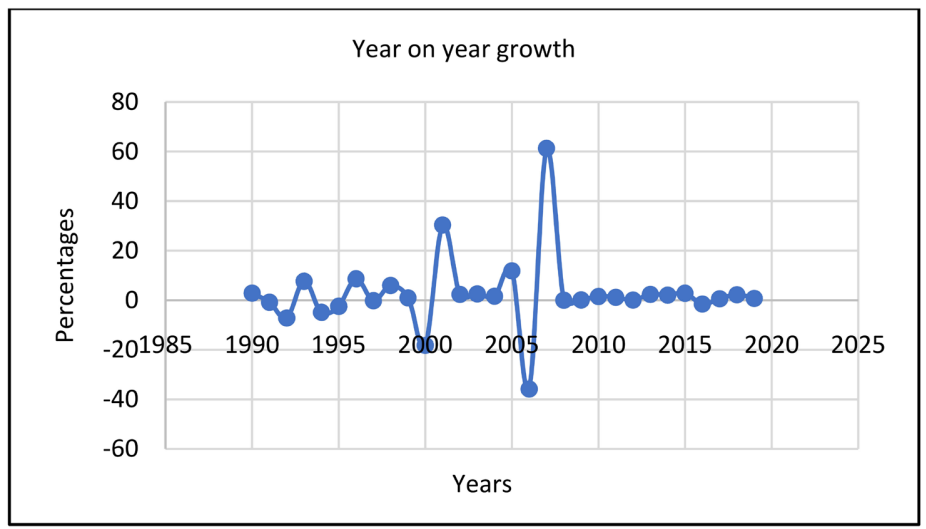

Figure 2. Year on Year growth rate of fish catch in Comoros. Source: General Office of Fisheries Resources.

Fishing is an important activity among the activities of Comoros Islands and contributes has always contributed to its development. In recent years motorized dugout canoes as well as outboard- and inboard-powered boats have been introduced into the fishery, and more efficient fishing tackle has become available. The more modern gear intended for use on pelagic fishes has added a new dimension to the fishery, thus fostering a yearly increase in fishermen, vessels as well as engine type. However, even though several measures have been employed to improve this ailing sector; including fishing tournaments, there has been less than significant changes seen in the fishing sector though fishes are available. Therefore, the present study intends to determine fishing performance in Comoros.

Fishing performance is one of the main issues in Comoros development, given that the environment allows fishing to take place, and as a result, it is very imperative to assess fishing performance in Comoros. theoretical literatures reviews indicated that many studies have been done on fishing performance, factors and its effects; [(Ombwa et al., 2018), studied the Socio-economic impacts of cage culture in Lake Victoria, (Grado, 2016) Fishing Activities and Economic Impacts of Charter Boat Businesses on the Mississippi Gulf Coast. (Mohamed Awad Abd, 2019), Factors Affecting Growth Performance of Nile Tilapia (O.niloticus). Fish Price Determination around Lake Victoria, Tanzania: Analysis of Factors Affecting Fish Landing Price (Melissa Hauzer 2013). Community-based governance of artisanal fisheries, Ngazidja Island, Comoros]. However, most of these studies differ on their methods applied, time frame, geography selected case study and the content. Also, reviews highlighted that fishes moved according to the location of the moon in comparison to their bodies (So lunar Theory). Comoros' fishing activity depends indeed on some inputs so that the economy can grow gradually. Some of these inputs though not limited to includes: Number of fishermen, Number of Vessels, Engine type, Price per kilo of fish and the Per Capita income in the country.

In this study we focus on one type of the tuna species known as Skipjack tuna 
since it represents $31 \%$ of its availability compared to other tuna species in waters of Comoro (Figure 3).

The skipjack tuna is a medium-sized perciform fish in the tuna family, Scombridae. It is a cosmopolitan pelagic fish found in tropical and warm-temperate waters. It is a very important species for fisheries. They are the smallest and most abundant of the major commercial tuna species, having a streamlined body that is mostly without scales. They are found mainly in the tropical areas of the Atlantic, Indian and Pacific Oceans, with the greatest abundance seen near the equator. Skipjack can live as long as eight to ten years and usually swim near the surface at night. They can breed year-round. It is a streamlined, fast-swimming pelagic fish, common in tropical waters throughout the world, and an important prey species for sharks and large pelagic fishes.

\section{Empirical Model}

A lot of studies have been done in Comoros including studies conducted in different countries around the world concerning fishing. The empirical results of these studies show that number of fishermen, vessel type, as well as engine type are very crucial inputs used for forecasting fish catch and to determine fishing performance. Moreover, there are studies focusing on particular inputs including Fish Price Determination around Lake Victoria, Fishing Activities and Economic Impacts of Charter Boat Businesses on the Mississippi Gulf Coast (Steve Grado et al., 2016). This study used multivariable DOLS model. The major advantage of this Model is that, it can statistically estimate relationships between different variables, and correlate how important each one is to the final outcome and where dependencies exist between them.

DOLS are superior to the OLS in many ways. OLS estimates may suffer from serial correlation, heteroskedasticity since the omitted dynamics are captured by the residual so that inference using the normal tables will not be valid -even asymptotically. DOLS however are usually preferred to the OLS estimator because they take care of small sample bias and endogeneity bias by taking the leads and lags of the first-differenced regressors. DOLS specification simply adds $p$ leads and $p$ lags of the first difference of dependent variable to the standard cointegrating regression. The addition of leads and lags removes the deleterious effects that short-run dynamics of the equilibrium process have on the estimate of the cointegrating vector

$$
Y_{t}=\lambda+\mu X_{t}+\sum_{i=q}^{i=q} \eta_{i} \Delta X_{t-i}+\omega_{t}
$$

where;

$$
\begin{aligned}
& Y_{t}: \text { dependent variable } \\
& X \text { : matrix of explanatory variables } \\
& \mu \text { : the long-run effect of a change in } X \text { on } Y \\
& q \text { : lead and lag length of regressors }
\end{aligned}
$$




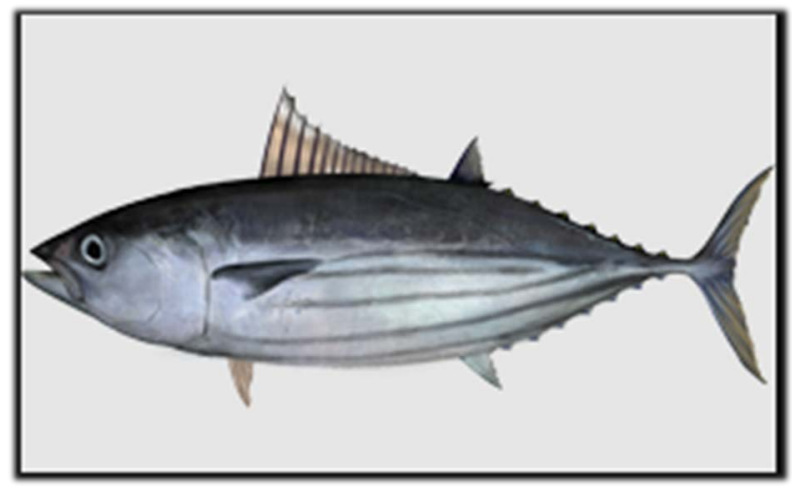

Figure 3. Skipjack tuna fish. Source: http://wikimedia.org/.

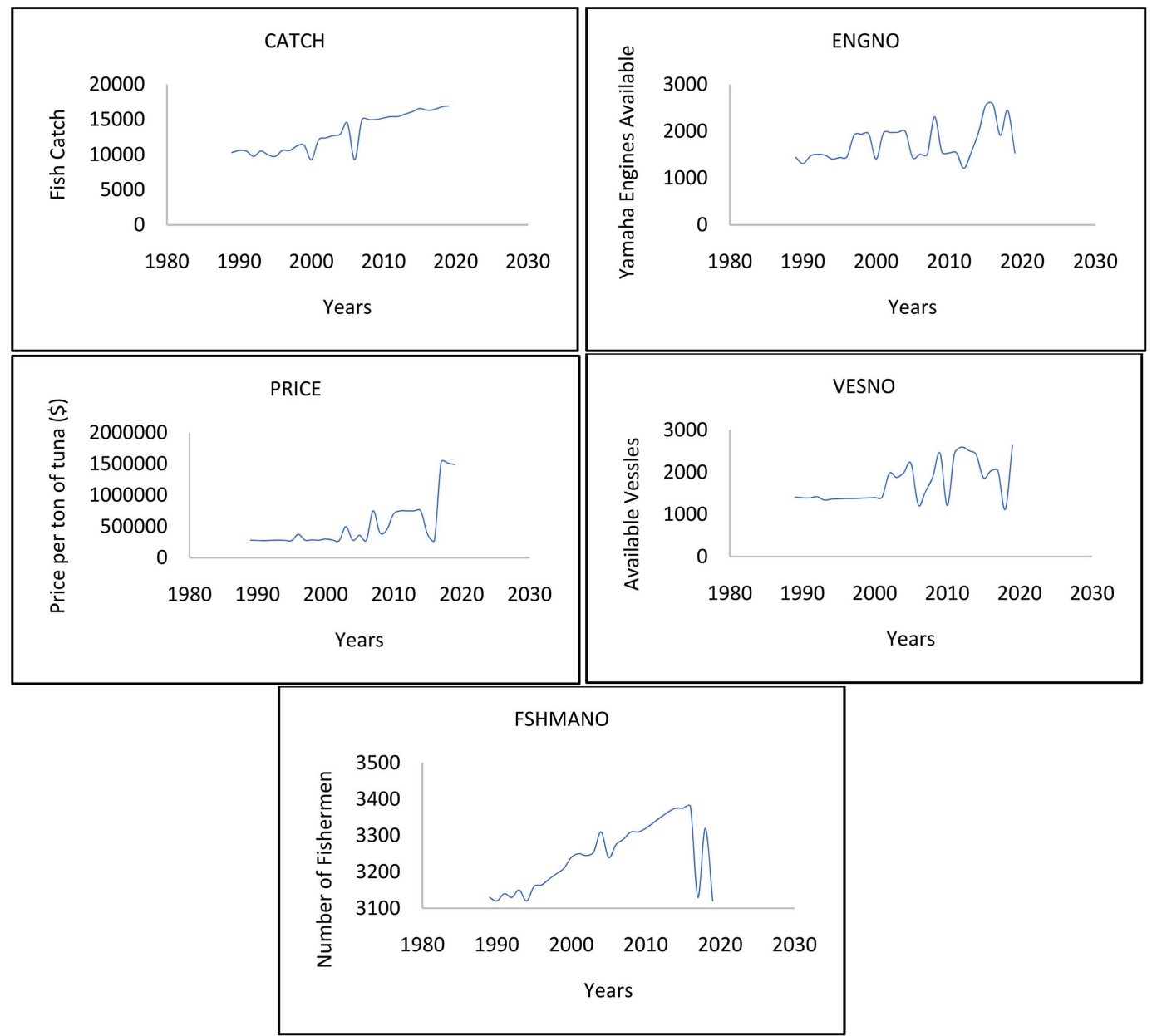

Figure 4. Graphical representation of variables.

\section{Analysis}

Running a regression while some factors in the model are non-stationary is likely to lead to spurious regression and inconsistent results. with such concern, the variables in the models were tested using the Augmented Dickey-Fuller (ADF) unit roots test, to know the underlying process that generate our time series variables, and the results obtained are presented in Table 1. 
Table 1. Augmented Dickey-Fuller unit root.

\begin{tabular}{|c|c|c|c|c|c|}
\hline \multicolumn{6}{|c|}{ unit root test } \\
\hline \multirow{2}{*}{ Variables } & \multicolumn{2}{|c|}{ level } & \multicolumn{2}{|c|}{ first difference } & \multirow{2}{*}{ order of integration } \\
\hline & coefficients & $\mathrm{p}$ value & coefficients & $\mathrm{p}$ value & \\
\hline Catch & -0.089204 & 0.9414 & -6.679953 & 0.0000 & $\mathrm{I}(1)$ \\
\hline Engine & -3.395540 & 0.0192 & -7.003605 & 0.0000 & $\mathrm{I}(0)$ \\
\hline Fishman & -1.504302 & 0.5173 & -11.21223 & 0.0000 & $\mathrm{I}(1)$ \\
\hline Price & -1.298401 & 0.6171 & -6.350721 & 0.0000 & $\mathrm{I}(1)$ \\
\hline Vessel & -3.439495 & 0.0173 & -8.311843 & 0.0000 & $\mathrm{I}(0)$ \\
\hline
\end{tabular}

From the table, it was clear that though variables for Vessel and engine number were stationary at level, the rest of the variables only became stationary after taking first difference. Establishing that there were variables which were of orders $\mathrm{I}(0)$ and $\mathrm{I}(\mathrm{I})$.

The Dynamic Ordinary Least Square (DOLS) developed by Stock \& Watson (1993), is handy in such situations, since it does not use instruments and produces unbiased estimates. It is also a cointegrating estimator that is applicable in scenario where we have a mixture of both $\mathrm{I}(0)$ and $\mathrm{I}(1)$ variables. DOLS are more appealing in small sample size dataset and very robust to deal with the problem of autocorrelation as well as the feedback effect from dependent to independent variable.

\section{Discussion of the Main Findings}

To examine the determinants of fishing performance in Comoros, this study adopted a simplified multivariate model, using the DOLS approach as presented in the following model.

$$
\begin{aligned}
\log (\text { Catch })_{t}= & \beta_{0}+\beta_{1} \log (\text { Vesno })_{t}+\beta_{2} \log (\text { Engno })_{t}+\beta_{3} \log (\text { Fshmano })_{t} \\
& +\beta_{4} \log (\text { price })_{t}+\sum_{j=-q}^{j=q} \alpha_{1} \Delta\left(\log (\text { Vesno })_{t-j}\right) \\
& +\sum_{j=-q}^{j=q} \alpha_{2} \Delta\left(\log (\text { Engno })_{t-j}\right)+\sum_{j=-q}^{j=q} \alpha_{3} \Delta\left(\log (\text { Fshmano })_{t-j}\right) \\
& +\sum_{j=-q}^{j=q} \alpha_{4} \Delta\left(\log (\text { price })_{t-j}\right)+\varepsilon_{t}
\end{aligned}
$$

Whereby, Catch ${ }_{t}$ denotes tonnage of fish catch per year, Vesno $_{t}$ is the number of fishing vessels available in a year, Engno ${ }_{t}$ represent the number of $30 \mathrm{HP}$ engine

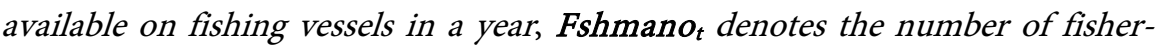
man available in a year while Price $_{t}$ denotes the selling price of fish per kilo.

For this research, the data used were annual secondary data with scope ranging from 1989 to 2019, collected from the records and existing data of the sectors for fishery in Comoros, which highly encouraged the use quantitative method. See Figure 4 these data include: Catches (Catch): which represent the total tonnage of Tuna fish caught at sea and returned to port, Number of fishermen 
(Fshmano): which represents those adult persons engagein fishing of tuna fish using motorised vessles. we expect that as more people join this activity, it will lead to an increase in fish caught.; Vessels number (Vesno): which represent the Number of Vessels registered for fishing Tuna and tuna type species in waters of Comoros; Engine number (Engno): which represent the number of vessels with engine of $30 \mathrm{HP}$ or higher. The types of engine used in the process of fishing especially tuna fish in Comoros, in the past were motorised engines of $15 \mathrm{HP}$ to 25 $\mathrm{HP}$ and they were YAMAHA type. Very recently engine of $30 \mathrm{HP}$ as well as 40 HP are being used. This type of engine allows the fishers to go far of shore with standard speed. Price (Price): This represents the price per ton of Comoros' tuna fish. Tuna fish price have largely remained unchanged over the 1990 years, however in recent past to present, prices have been very unpredictable and volatile.

Table 2 presents the results of the estimated model.

The study intended to investigate determinant of fishing performance in Comoros. The regression results from DOLS analysis reveal a mixture of relationship. Three of the four independent variables indicated a positive relationship with the dependent variable; the number of available engines, the number of fishermen and the price of fish did have a positive influence on fish catch. However, of the three, only the price variable is significant in determining the fish catch. For every $1 \%$ rise in the price fish, the catch is estimated to increase by $28.3 \%$. More fishers are also expected to increase catch; more so the structural makeup of the fishers is important in that a youthful and educated fishers perform better than an aged and less educated one. Furthermore, the number of vessels is a negative determinant of fish catch; the more fishing vessels that are out fishing, the higher the tendency of depletion of the available fish, and hence a reduction in catch. In fact, as more vessel get involve in fishing, the possibility of some going rouge increases, undermining the catch level. In the same sense however, the more fishing vessels acquire the right engine (technology), the farther they can go out at sea and their chances to a better catch increase. This result is consistent with Xia and Gong (2014). Graphical representation of fish catch variables is shown in Figure 1.

From the output of the DOLS estimation, we perform the cointegration test in order to determine whether there exists a long run convergence of the model. The null and alternative hypothesis of the Engle-Granger state that:

\section{$H_{o}$ : There is no cointegration between the variables}

\section{$H_{1}: H_{0}$ is not true}

The result of the test is presented in Table 3.

The test for cointegration revealed that the regressors in the model have a long-run relationship since they were cointegrated, and reject the null hypothesis of no cointegration. Indicating that the relationship between variables in our model is far from being spurious, instead can be relied upon for prediction purposes. 
A normality test was done with the null hypothesis that the values are sample from a population that follows a normal distribution and the alternative hypothesis stating that the reverse is true. From the test, we were unable to rejecr the null hypothesis hence concluding that the sampled data is not inconsistent with a normal distribution. The output of the test for normality is presented in Figure 5.

Table 2. Dynamic Least Squares (DOLS) model estimates.

\begin{tabular}{ccccc}
\hline \multicolumn{5}{c}{ Dependent Variable: LOG (CATCH) } \\
\hline \multicolumn{5}{c}{ Method: Dynamic Least Squares (DOLS) } \\
\hline \multicolumn{4}{c}{ Fixed leads and lags specification (lead = 1, lag =1) } \\
\hline Variable & Coefficient & Std. Error & t-Statistic & Prob. \\
LOG (VESNO) & -0.059006 & 0.216641 & -0.272366 & 0.7904 \\
LOG (ENGNO) & 0.006414 & 0.206615 & 0.031043 & 0.9758 \\
LOG (FSHMANO) & 3.773057 & 2.368358 & 1.593111 & 0.1394 \\
LOG (PRICE) & 0.283326 & 0.109415 & 2.589453 & 0.0252 \\
C & -24.30912 & 15.89848 & -1.529022 & 0.1545 \\
R-squared & 0.956487 & Mean dependent var & 9.459443 \\
Adjusted R-squared & 0.893195 & S.D. dependent var & 0.206155 \\
S.E. of regression & 0.067374 & Sum squared resid & 0.049931 \\
Long-run variance & 0.003427 & & \\
\hline
\end{tabular}

Table 3. Engle-Granger Cointegration test.

\section{Cointegration Test Engle-Granger}

Null hypothesis: Series are not cointegrated

\begin{tabular}{ccc}
\hline Automatic lag specification (lag $=0$ based on Schwarz Info Criterion, maxlag = 5) \\
\hline & Value & Prob. $^{*}$ \\
\hline Engle-Granger tau-statistic & -6.299361 & 0.0031 \\
Engle-Granger z-statistic & -34.63334 & 0.0026 \\
\hline
\end{tabular}

${ }^{*}$ MacKinnon (1996) p-values.

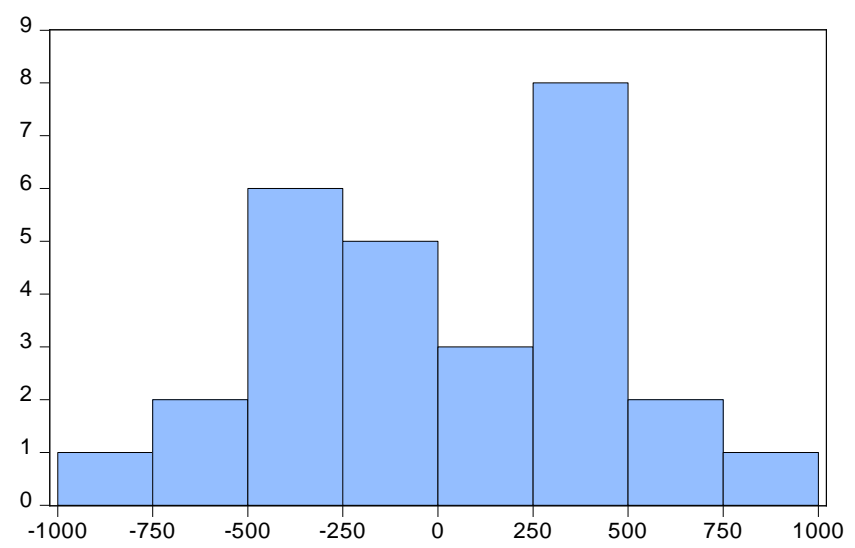

\begin{tabular}{|lr|}
\hline \multicolumn{2}{|l|}{ Series: Residuals } \\
Sample 1991 2018 \\
Observations 28 \\
Mean & $-6.76 \mathrm{e}-12$ \\
Median & -66.07728 \\
Maximum & 766.5016 \\
Minimum & -933.5700 \\
Std. Dev. & 437.3400 \\
Skewness & -0.103080 \\
Kurtosis & 2.042209 \\
& \\
Jarque-Bera & 1.119842 \\
Probability & 0.571254
\end{tabular}

Figure 5. Jarque-Bera normality test. 
Since in small, or finite, samples, the $t, F$, and chi-square tests require the normality assumption, it is important that this assumption be checked formally. Application of the Jarque-Bera test shows that the JB statistic is about 1.1189, and the probability of obtaining such a statistic under the normality assumption is about 57 percent. As the figure shows, the residuals from the Fish catch regression seem to be symmetrically distributed. Therefore, we do not reject the hypothesis that the error terms are normally distributed.

\section{Conclusion}

The intention of this work is to determine factors influencing fish catch in the Comoros. Four important variables were identified as factors based on reviewed literatures and were subjected to the DOLS analysis. However, with the profound limited government support, lack of proper place for post fishing activities, market chain problem, and illegal fishers which are considered to be amongst the main problems of the Comoros fishers, the selling price of fish and the number of fishers and technology they employed ( $25 \mathrm{hp}$ engine) were identified as positive trigger for fish catch. In fact, emphasis is placed on the pricing policy of fish since it is a significant motivating factor for fish catch. Furthermore, we stress the importance of controlling illegal fishers, while also encourages efficient government support based on clear understanding of the needs of fishers in Comoros to reduce problem and enhance current catch levels that maintain a higher yearly potential yield. The number of fishing vessels in Comoros should be regulated to reduce if not eliminating its negative pull on the fish catch while at the same time encouraging the use of technology.

\section{Conflicts of Interest}

The authors declare no conflicts of interest regarding the publication of this paper.

\section{References}

Aura, O.V. et al. (2018) Integration of Mapping and Socio-Economic Status of Cage Culture: Towards Balancing Lake-Use and Culture Fisheries in Lake Victoria, Kenya. Aquaculture Research, 49, 532-545. https://doi.org/10.1111/are.13484

Bakar, A. S. (2013). Fishery Exports and the Economic Development of LDCs. Taylor \& Francis Ltd.

Fujii, H. et al. (2014). Fisheries in the ESA-IO Region. Ngasaki Press.

Grado, S. et al. (2016). Fishing Activities and Economic Impacts of Charter Boat Businesses on the Mississippi Gulf Coast. Proceedings of the Southeastern Association of Fish and Wildlife Agencies, 57, 112-123.

Hauzer, M., Dearden, P., \& Murray, G. (2013). The Effectiveness of Community-Based Governance of Small-Scale Fisheries, Ngazidja Island, Comoros. Marine Policy, 38, 346-354. https://doi.org/10.1016/j.marpol.2012.06.012

Salih, M. A. A. A. (2019). Factors Affecting Growth Performance of Nile Tilapia (O. niloticus) Fingerlings Cultured in Tanks. Ph.D. Thesis, Sudan University of Science and 
Technology (SUST).

Sulaiman, N. A. A. (2018). Fisherman's Knowledge of the Moon Phenomenon in Fishing Activities. International Journal of Academic Research in Business and Social Science, $8,941-949$.

Xia, B. S., \& Gong, P. (2014). Review of Business through Data Analysis. Benchmarking Press. 